\title{
USO DE LAGOA AERADA FACULTATIVA COMO POLIMENTO DO REATOR ANAERÓBIO DE MANTA DE LODO UASB NO TRATAMENTO DE DEJETOS DE SUÍNOS EM ESCALA LABORATORIAL
}

\author{
The efficiency of an aerated pond used for treating the effluent of an UASB reactor \\ (upflow anaerobic sludge blanket reactor) treating swine manure in a lab-scale system
}

\author{
Fernanda Ribeiro do Carmo ${ }^{1}$, Cláudio Milton Montenegro Campos ${ }^{2}$, \\ Cláudio Gouvêa Botelho ${ }^{3}$, Claudionor Camilo da Costa ${ }^{4}$
}

\begin{abstract}
RESUMO
As atividades agroindustriais têm se voltado não somente para o aumento da produtividade, mas também para a conservação do meio ambiente. A suinocultura é, sem dúvida, uma das atividades agroindustriais mais poluidoras, principalmente no Estado de Minas Gerais. Sendo assim, objetivou-se desenvolver e operar uma Lagoa Aerada Facultativa (LAF) em escala de bancada (laboratorial), e como polimento de um Reator Anaeróbio de Manta de Lodo (UASB), visando a tratar os dejetos de suínos com máxima eficiência e custo mínimo. O experimento foi conduzido no Laboratório de Análise de Água do Departamento de Engenharia (LAADEG) da Universidade Federal de Lavras (UFLA), sendo composto por um tanque de acidificação e equalização (TAE), um reator anaeróbio de manta de lodo (UASB) e uma lagoa aerada facultativa (LAF) para polimento. As análises fisico-químicas realizadas foram: $\mathrm{pH}, \mathrm{DBO}_{5}, \mathrm{DQO}_{\mathrm{T}}$, Sólidos Totais (fixos e voláteis), Temperatura, Nitrogênio, Fósforo, Alcalinidade e Acidez Total. A unidade LAF mostrou uma eficiência média de 83 e $42 \%$ de $\mathrm{DQO}_{\mathrm{T}}$ e Nitrogênio Total, respectivamente. O sistema proporcionou remoção média de 93, 84 e 85\% de $\mathrm{DQO}_{\mathrm{T}}, \mathrm{DBO}_{5}$ e Sólidos Totais Voláteis, respectivamente.
\end{abstract}

Termos para indexação: Efluentes suinícolas, poluição, lagoas de estabilização.

\begin{abstract}
Nowadays the agro-industry activities have not only focused its direction to the production increasing, but also, to the environmental preservation. The swine production is amo doubt, an activity, which can be considered, one of the most pollutants, mainly in the Minas Gerais State (BRAZIL). Therefore, this research aimed at developing and operating an Upflow Anaerobic Sludge Blanket Reactor (UASB), followed by an Aerobic Facultative Pound (AFP) (Lab-Scale), with the objective of treating the liquid effluent originated from swine with the maximum efficiency and lower costs. The experiment was carried out in the Laboratory of Water Analysis of the Engineering Department of the Federal University of Lavras (UFLA). The system was assembled with an Acidification Equalization Tank (AET), an UASB reactor and an Aerobic Facultative Pound (AFP) for polishing the UASB effluent. The physical-chemical analysis carried out through out the experiment, were: $\mathrm{pH}$, $\mathrm{BOD}_{5}, \mathrm{COD}_{\mathrm{T}}$, Total Solids, Temperature, Nitrogen, Phosphorus, Alkalinity, and total acidity. The AFP unity showed an average efficiency of 83 and $42 \%$ for remooing $\mathrm{COD}_{\mathrm{T}}$ and total Nitrogen, respectively. The whole system operated with an average of 93,84 and $85 \%$ of $\mathrm{COD}_{\mathrm{T}}, \mathrm{BOD}_{5}$ and Total Volatile Solids, respectively.
\end{abstract}

Index terms: Swine manure, aerobic facultative pound, swine liquid effluent.

(Recebido para publicação em 17 de março de 2003 e aprovado em 29 de abril de 2003)

\section{INTRODUÇÃO}

No meio rural, a suinocultura vem sendo considerada como um dos segmentos mais preocupantes, por causa do aumento do rebanho que, no Brasil, passou de 26,5 milhões em 1993, pa- ra 37,7 milhões de cabeças em 2001 (ABIPECS, 2002).

Em reportagem apresentada pela revista VEJA (TEICH, 2002), o jornalista Daniel Hessel Teich afirmou que em certas regiões do mundo mais da metade dos rios está poluída por dejetos, resíduos indus-

\footnotetext{
1. Bolsista do CNPq - Departamento de Engenharia da Universidade Federal de Lavras/UFLA - Caixa Postal 37 - 37200-000 - Lavras, MG.

2. Professor Adjunto III, Ph.D., Departamento de Engenharia da UFLA.

3. Professor Adjunto IV, M.Sc., Departamento de Engenharia da UFLA.

4. Doutorando em Engenharia Agrícola da UFLA.
} 
triais e agrotóxicos e ainda que nove de cada dez litros de água utilizados no Terceiro Mundo são devolvidos à natureza sem nenhum tipo de tratamento. Diante desse quadro, constata-se a necessidade de se buscar o desenvolvimento de tecnologias alternativas para reduzir o poder poluidor dos resíduos orgânicos, sobretudo dos efluentes de suinoculturas.

Nesse sentido, os reatores UASB são uma boa alternativa para tratamentos de efluentes poluidos, pois operam com baixos TDH, possuem simplicidade construtiva e de operação e ainda produzem como subproduto da digestão anaeróbia o biogás, o qual pode ser usado como fonte alternativa de energia (CAMPOS, 1990). No entanto, apenas essa unidade é, na maioria das vezes, insuficiente na remoção da carga poluidora exigida pelos órgãos ambientais, tendo o efluente a necessidade de pós-tratamento (polimento).

Entre as alternativas de pós-tratamento, uma que se destaca é o uso das lagoas de estabilização, já que essas mantêm a simplicidade conceitual de todo conjunto. Essa unidade de tratamento tem potencial para ser utilizada pelos pequenos produtores rurais por possuir uma tecnologia relativamente simples, tornando-se fácil o monitoramento (CARMO et al., 2002).

O tratamento de efluentes líquidos suinícola não está ainda ambientalmente resolvido, e até o momento, continua sendo um desafio mundial, resultando no fechamento de granjas na Holanda e Alemanha, diante dos impactos ambientais provocados pela atividade (BLEY JÚNIOR, 2000).

Neste trabalho adotou-se o termo "dejetos de suínos" aos excrementos frescos, incluindo fezes e urina mais o material de cama, restos de alimentos, água e produtos químicos utilizados para a limpeza das baias de confinamento.
Segundo Sperling (1996), a Lagoa Aerada Facultativa (LAF) é um sistema predominantemente aeróbio, no qual o oxigênio é obtido através de aeradores. É denominada facultativa pelo fato de que o nível de energia introduzida pelos aeradores é suficiente apenas para a oxigenação da parte superior da lagoa; portanto, não mantém os sólidos (bactéria e sólidos em suspensão do esgoto bruto) dispersos em toda massa líquida. Os sólidos tendem a sedimentar e, assim, transformam-se na camada de lodo do fundo a ser decomposta anaerobiamente.

O turbilhonamento causado pela injeção de ar propicia a penetração do oxigênio atmosférico na massa líquida e proporciona a estabilização da matéria orgânica mais rapidamente, resultando num menor tempo de detenção hidráulica e menor requisito de área do que as lagoas aeróbias ou facultativas.

\section{OBJETIVOS}

Objetivou-se com esta pesquisa o desenvolvimento e operação de uma Lagoa Aerada Facultativa (LAF) em escala laboratorial instalada após a unidade RAMAL/UASB, visando a pesquisar a eficiência dessa lagoa no polimento do referido efluente, com a remoção adicional da $\mathrm{DBO}_{5}$, nutrientes e patógenos.

\section{MATERIAL E MÉTODOS}

A pesquisa foi desenvolvida no Laboratório de Análise de Água do Departamento de Engenharia (LAADEG) da Universidade Federal de Lavras (UFLA), durante 250 dias.

O efluente foi coletado nas instalações suinícolas localizadas na área experimental do Departamento de Zootecnia da UFLA. O experimento foi construído em vidro, recipientes plásticos, tubos, mangueiras, materiais vedantes, torneiras e registros, possuindo as seguintes unidades (Figura 1). 


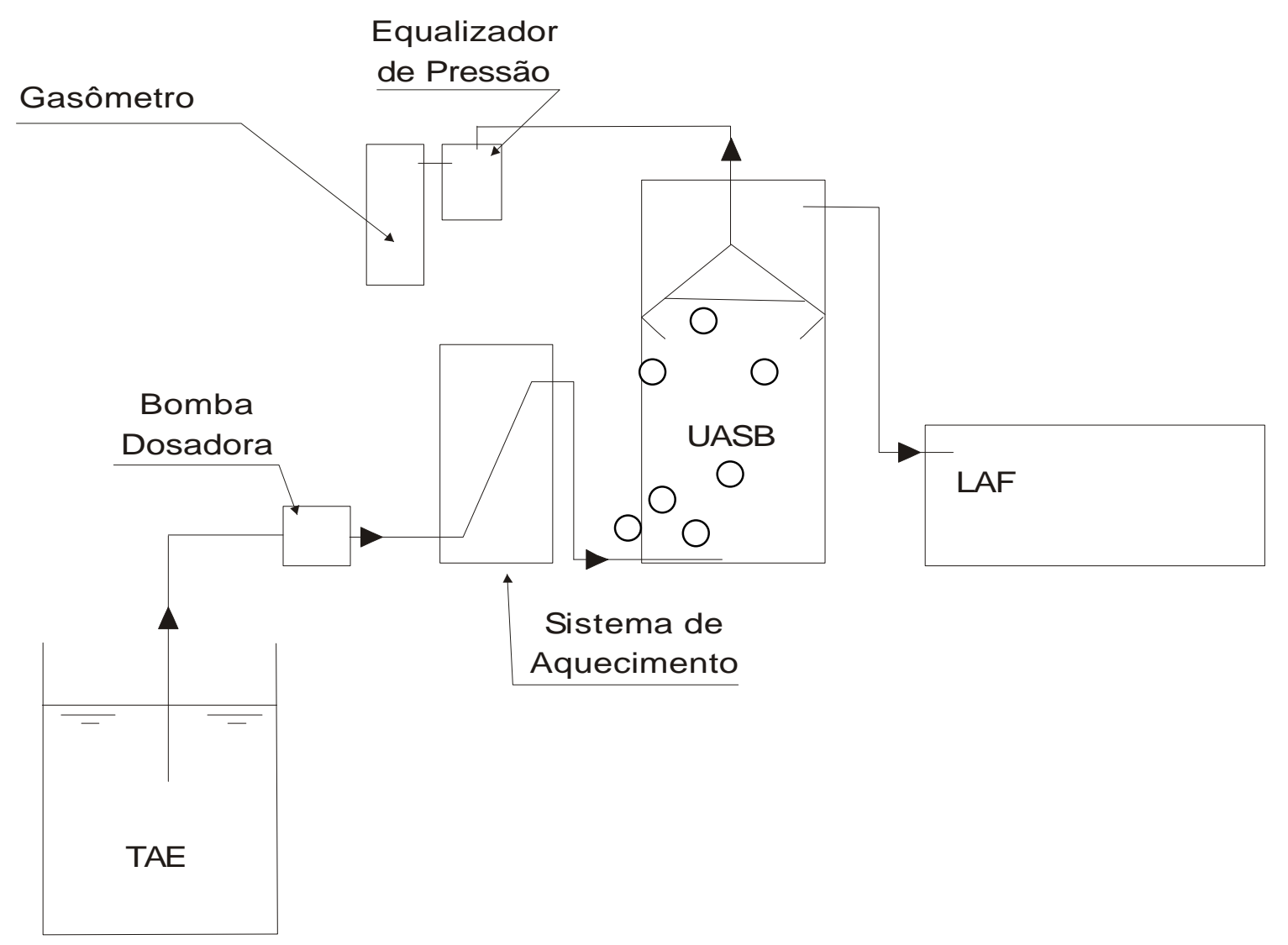

FIGURA 1 - Desenho esquemático do sistema de bancada.

- Tanque de Acidificação e Equalização (TAE): nessa unidade ocorrem as primeiras etapas da digestão anaeróbia dos compostos complexos inerentes aos dejetos (proteínas, carboidratos, lipídeos, entre outros). O recipiente foi confeccionado com plástico e possuía o volume útil de 38 litros.

- Sistema de Alimentação: realizado por uma bomba dosadora, marca PROMINENT, modelo GALA 1601 e uma pressão de 10 bars.

- Sistema de Aquecimento: instalado com a finalidade de aquecer o afluente do reator UASB a níveis mesófilos $\left(25 \mathrm{a} 40^{\circ} \mathrm{C}\right)$ e, assim, acelerar as atividades bacterianas. Construído em vidro, com volume de 7,9 litros, tendo no seu interior uma serpentina de cobre em forma de espiral, pela qual o efluente era introduzido. Imerso na parte líquida desse recipiente foi instalado um boiler com termostato, no qual era pré-fixada a temperatura.
- Reator (RAMAL/UASB): em escala de bancada, foi construído em vidro com volume útil de 11,72 litros. Ao longo desse reator, foram instalados registros eqüidistantes que funcionavam como amostradores, para a caracterização do perfil do lodo. A parte superior possuía um separador de faces (líquido, sólidos e gás), em forma piramidal. O nível do líquido dentro desse separador era mantido por meio de um equalizador de pressão, constituído por um reservatório também em vidro.

- Lagoa Aerada Facultativa: para polimento do efluente do UASB foi construída uma lagoa aerada facultativa em vidro, com volume útil de 16 litros. Ao longo de sua extensão, foram instaladas mangueiras com diâmetro interno de $0,5 \mathrm{~cm}$, com pequenas perfurações eqüidistantes de $0,5 \mathrm{~cm}$, por onde era injetado o ar no sistema.

- Sistema de Armazenamento de Biogás (gasômetro): construído de vidro, sendo hermeticamente fe- 
chado, contendo três registros de agulha com volume útil de 16 litros. O processo de medição foi por deslocamento líquido.

As análises foram efetuadas no Laboratório de Análise de Água do Departamento de Engenharia da Universidade Federal de Lavras (LAAGEG/UFLA), segundo o APHA (1998).

Os parâmetros físico-químicos e operacionais analisados foram: $\mathrm{pH}$, temperatura, vazão, medição de volume de biogás, demanda química de oxigênio $\left(\mathrm{DQO}_{\mathrm{T}}\right)$, demanda bioquímica de oxigênio $\left(\mathrm{DBO}_{5}^{20}\right)$, sólidos totais (ST), sólidos totais fixos (STF), sólidos totais voláteis (STV), nitrogênio total, fósforo total, acidez total e alcalinidade total.

\section{RESULTADOS E DISCUSSÃO}

Os dados analisados são referentes a 250 dias de operação, e as médias relacionadas com o afluente e efluentes da LAF estão apresentadas na Tabela 1.

\section{pH}

$\mathrm{O}$ valor médio de $\mathrm{pH}$ observado no afluente e efluente da LAF foi de 7,72 e 7,27, respectivamente. Nota-se ainda que houve poucas variações, o que contribuiu positivamente para a aclimatização dos microorganismos, cuja faixa ideal varia de 5,0 a 7,4. Isso demonstra que o uso da LAF como polimento do reator é propenso a um menor custo de monitoramento devido a sua capacidade de tamponamento, como pode ser observado na Figura 2.

\section{Temperatura}

$\mathrm{O}$ valor médio de temperatura no afluente e efluente da $\mathrm{LAF}$ foi de 24,9 e $24,0^{\circ} \mathrm{C}$, respectivamente. A temperatura média ambiente foi de $22,7^{\circ} \mathrm{C}$. As variações de temperatura na LAF podem ser visualizadas na Figura 3. A oscilação se deve a fatores externos provocados principalmente pelas estações de inverno e verão.

TABELA 1 - Média dos parâmetros operacionais obtidos nas tomadas afluente (A) e efluente (E) da LAF.

\begin{tabular}{|c|c|c|c|c|c|c|c|c|c|c|c|c|c|c|}
\hline \multirow{2}{*}{$\mathrm{TDH}$} & \multicolumn{2}{|c|}{$\mathrm{pH}$} & \multicolumn{2}{|c|}{$T \stackrel{\circ}{ } \mathrm{C}$} & \multicolumn{2}{|c|}{$\mathrm{DQO}_{T(\mathrm{~m} g / \mathrm{L})}$} & \multirow{2}{*}{$\frac{\mathrm{DBO}_{5(\mathrm{mg} / \mathrm{L})}}{\mathrm{A}-\mathrm{LAF}}$} & \multirow{2}{*}{$\frac{\text { COV }}{\left(m_{3} / m_{3} \cdot d\right)}$} & \multirow{2}{*}{$\frac{\mathrm{CHV}}{\left(\mathrm{m}_{3} / \mathrm{m}_{3} \cdot \mathrm{d}\right)}$} & \multirow{2}{*}{$\begin{array}{l}\text { Vazão } \\
\left(\mathrm{m}^{3} / \mathrm{d}\right)\end{array}$} & \multicolumn{2}{|c|}{ NT (mg/L) } & \multicolumn{2}{|c|}{$\mathrm{PT}(\mathrm{mg} / \mathrm{L})$} \\
\hline & A-LAF & E-LAF & A-LAF & E-LAF & A-LAF & E-LAF & & & & & A-LAF & E-LAF & A-LAF & E-LAF \\
\hline 55 & 7,63 & 6,52 & 23,1 & 21,4 & 216 & 51 & 58 & 0,072 & 0,3144 & 0,513 & - & - & - & - \\
\hline 40 & 7,39 & 7,30 & 24,0 & 23,3 & 147 & 37 & 35 & 0,072 & 0,4396 & 0,560 & 190 & - & - & - \\
\hline 30 & 7,82 & 7,50 & 25,2 & 24,9 & 213 & 18 & 187 & 0,072 & 0,5088 & 0,598 & 203 & 136 & 9 & 7,8 \\
\hline 25 & 7,78 & 6,87 & 26,0 & 25,6 & 432 & 48 & 35 & 0,072 & 0,7016 & 0,615 & 262 & 209 & 11 & 13 \\
\hline 18 & 7,78 & 7,33 & 26,7 & 25,9 & 121 & 41 & 22 & 0,120 & 1,0073 & 0,620 & 425 & - & 13 & 7,6 \\
\hline 15 & 7,94 & 8,12 & 24,5 & 23,1 & 407 & 60 & 34 & 0,384 & 1,0712 & 0,554 & - & - & - & - \\
\hline
\end{tabular}

* (-) parâmetros não analisados nos respectivos TDH

* Todas as siglas utilizadas na tabela serão explicitadas no decorrer da discussão.

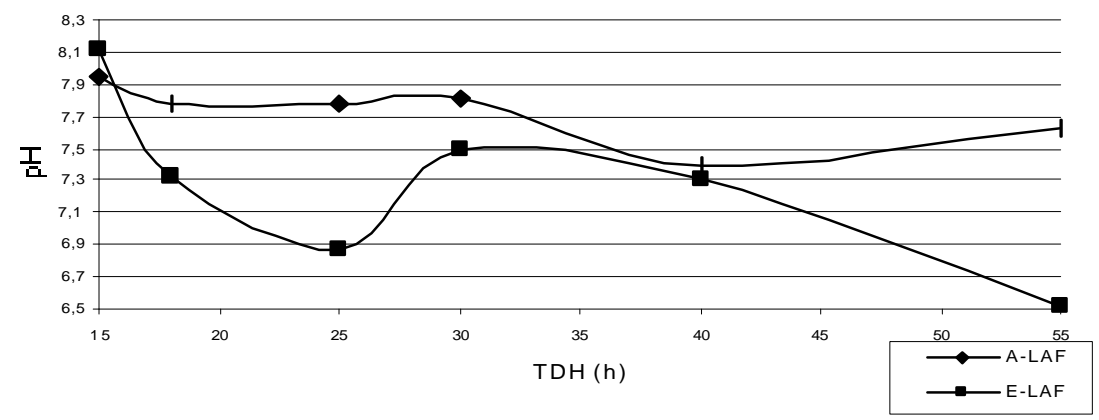

FIGURA 2 - Variação média do pH afluente (A) e efluente(E) da LAF em função dos tempos de detenção hidráulica (TDH) adotados. 


\section{Vazão}

A vazão do sistema foi determinada tendo como base o tempo de detenção hidráulica adotado. A vazão mínima e máxima foi 0,003 e $0,03 \mathrm{~m}^{3} \mathrm{~d}^{-1}$, respectivamente, com valor médio de $0,01 \mathrm{~m}^{3} \mathrm{~d}^{-1}$. Esses valores podem ser observados na Figura 4.

\section{Carga Hidráulica Volumétrica (CHV)}

Com relação a $\mathrm{CHV}$, as variações podem ser visualizadas na Figura 5. Valores de CHV muitos elevados podem causar varredura de biomassa do sistema e prejudicar seu funcionamento (CHERNICHARO, 1997). O valor médio da CHV na LAF foi $0,7 \mathrm{~m}^{3} \mathrm{~m}^{-3} \mathrm{~d}^{1}$.

\section{Demanda Química de Oxigênio}

Segundo Sperarling (1996), a Demanda Química de Oxigênio representa a quantidade de oxigênio ne- cessária para estabilizar quimicamente a matéria orgânica carbonácea. Os valores médios da DQO afluente e efluente da LAF foram iguais a 256 e $43 \mathrm{mgDQO}_{\mathrm{T}} / \mathrm{L}$, respectivamente, os quais estão representados na Figura 6. A eficiência média na remoção da DQO na LAF foi $83 \%$, resultando numa eficiência do sistema em torno de $93 \%$.

\section{Carga Orgânica Volumétrica (COV)}

Define-se COV como a quantidade de matéria orgânica aplicada por unidade de volume do reator. O valor médio da COV da LAF foi de 0,120 $\mathrm{kg} \mathrm{m}^{-3} \mathrm{~d}^{-1}$, representado na Figura 7. Altas COV podem causar problemas de estabilidade no sistema em razão de possível varredura de lodo, ou seja, a expulsão dos microrganismos responsáveis pelo processo da digestão anaeróbia (CHERNICHARO, 1997).

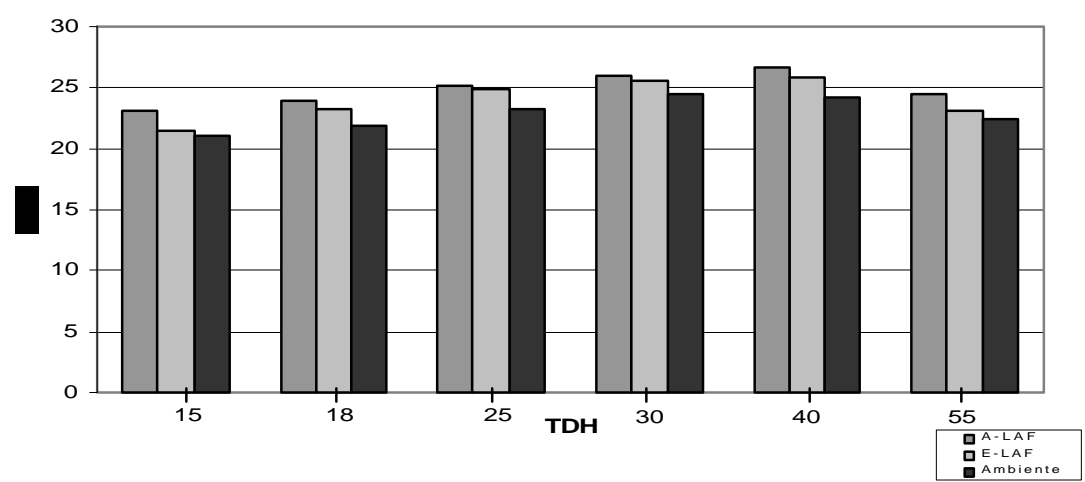

FIGURA 3 - Variação média da temperatura na LAF em função dos tempos de detenção hidráulica adotados (TDH) e valores da temperatura externa.

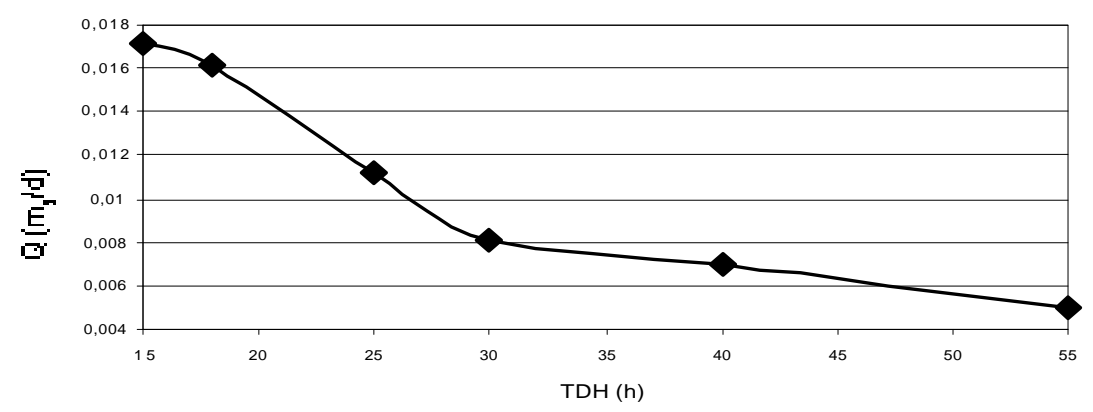

FIGURA 4 - Variação da vazão média do sistema em função dos tempos de detenção hidráulica (TDH) adotados. 


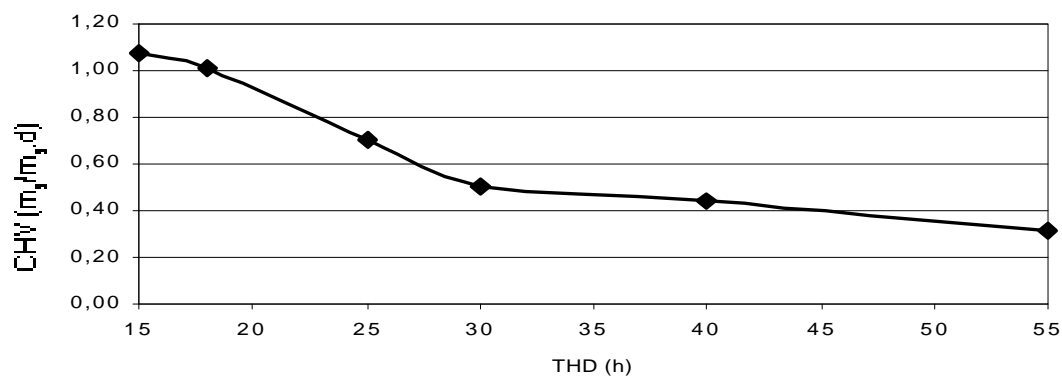

FIGURA 5 - Variação média da Carga Hidráulica Volumétrica na LAF em função dos tempos de detenção hidráulica (TDH) adotados.

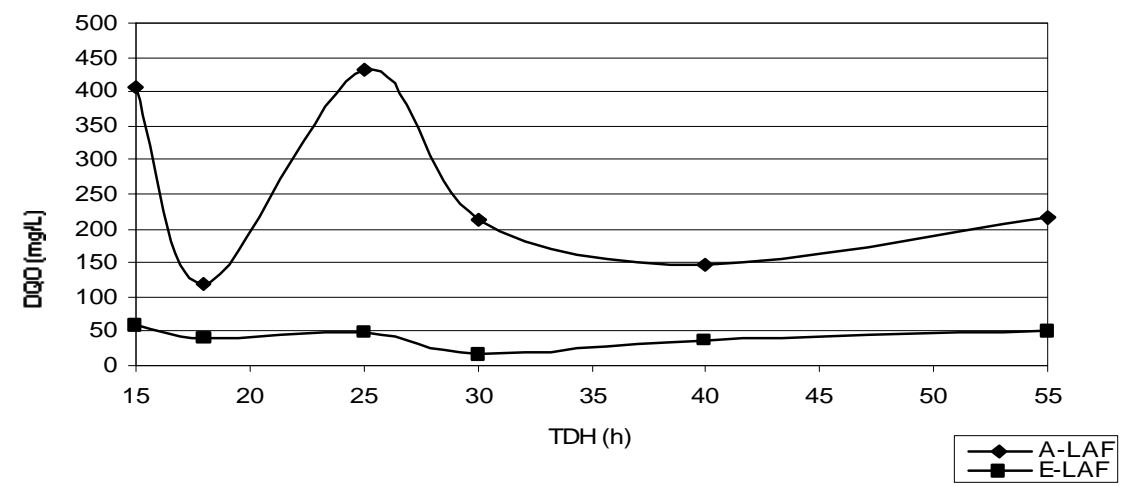

FIGURA 6 - Variação média da DQO nas tomadas afluente (A) e efluente (E) da LAF em função dos tempos de detenção hidráulica (TDH) adotados.

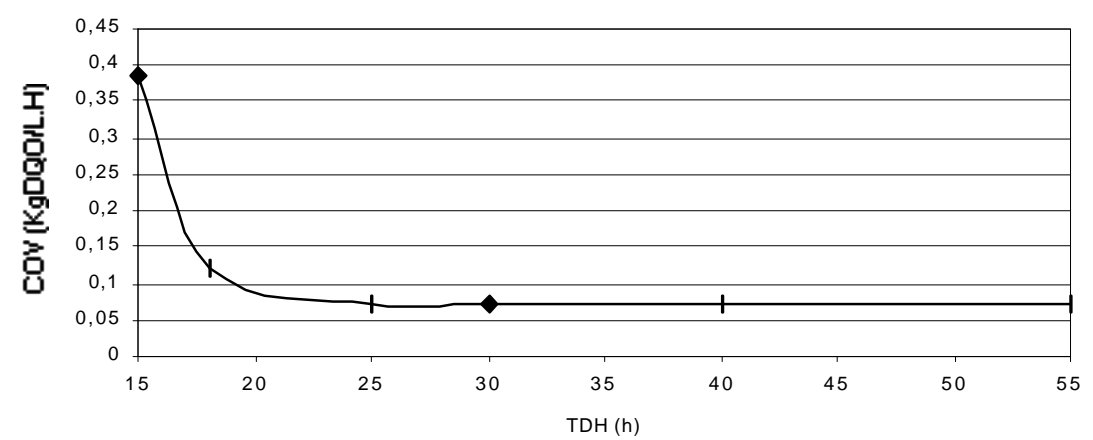

FIGURA 7 - Variação média da Carga Orgânica Volumétrica da LAF em função dos tempos de detenção hidráulica (TDH) adotados. 
Sólidos totais (ST), Sólidos totais fixos (STF) e Sólidos totais voláteis (STV)

As concentrações médias de ST, STF e STV no afluente da LAF foram de 718,470 e $250 \mathrm{mgL}^{-1}$, respectivamente, e as concentrações médias de ST, STF e STV no efluente da LAF foram de 760, 490 e 270 mg.L ${ }^{-1}$, respectivamente. Como pode ser visualizado na Figura 9, não houve eficiência de remoção por causa do arraste de sólidos. O sistema como um todo apresentou eficiência média na remoção de ST, STF e STV de 69, 29 e $85 \%$, respectivamente.

\section{Nitrogênio Total e Fósforo Total}

Segundo a Sociedade Brasileira de Zootecnia, os dejetos suínos possuem poder poluente até 500 vezes superior ao do esgoto doméstico e são bem mais ricos em nitrogênio, fósforo e potássio. Os valores médios da concentração de nitrogênio no afluente e no efluente da
LAF, analisados somente nos TDH de 40, 30, 25 e 18 horas, foram de 258 e $151 \mathrm{mgN} . \mathrm{L}^{-1}$, respectivamente. Os valores médios da concentração de fósforo no afluente e no efluente da LAF foram 10,5 e $11 \mathrm{mgP.L}^{-1}$, respectivamente. $\mathrm{O}$ aumento de fósforo na saída da LAF demonstra que houve evasão de sólidos no efluente, principalmente durante a faixa de TDH correspondente a 18 e 25 horas. A eficiência da LAF na remoção de nitrogênio total foi de $41 \%$. De acordo com os valores dos parâmetros acima citados, encontrou-se uma relação entre a $\mathrm{DQO}_{\mathrm{T}}$, NT e PT, no afluente da LAF, da ordem de 1:1:25, aproximadamente, já no efluente da LAF, a relação entre a $\mathrm{DQO}_{\mathrm{T}}, \mathrm{NT}$ e PT foi de 4:14:1. No efluente, o valor médio do NT foi maior do que a $\mathrm{DQO}_{\mathrm{T}}$ provavelmente porque o valor médio da $\mathrm{DQO}_{\mathrm{T}}$ foi realizado com todos os TDH, já os valores de NT somente foram analisados a partir do TDH de 30 horas, por falta de uma metodologia especifica. As variações da concentração de nitrogênio e fósforo podem ser observadas na Figura 11 e 12 respectivamente.

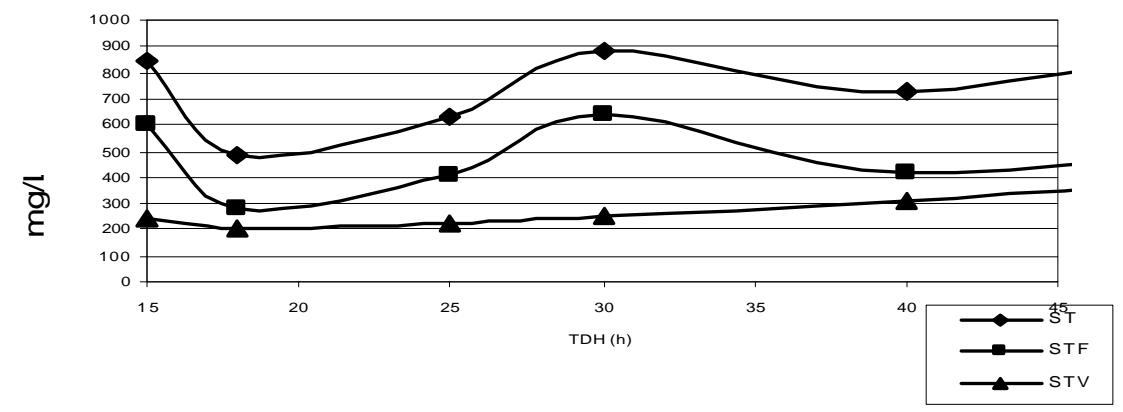

FIGURA 9 - Variação média dos sólidos efluente na LAF em função dos tempos de detenção hidráulica (TDH) adotados.

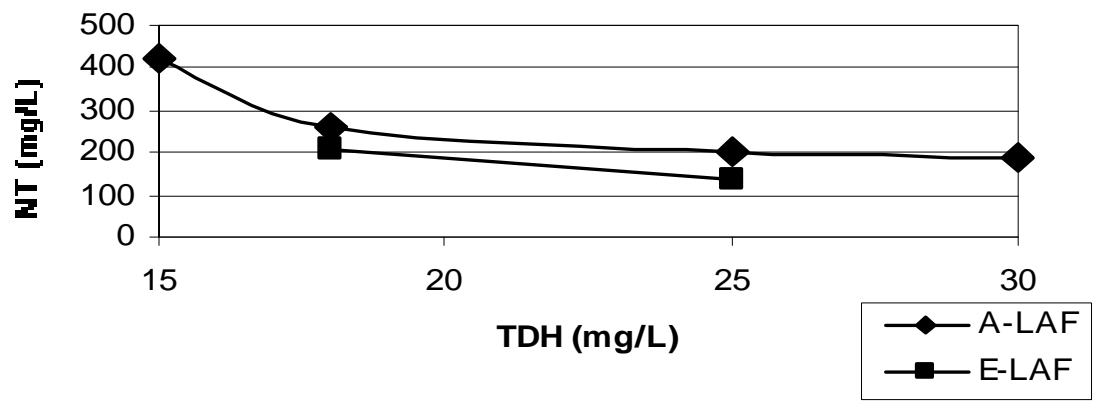

FIGURA 11 - Variação média do Nitrogênio Total afluente (A) e efluente (E) da LAF em função dos TDH adotados.

Ciênc. agrotec., Lavras, v. 28, n. 3, p. 600-607, maio/jun., 2004 


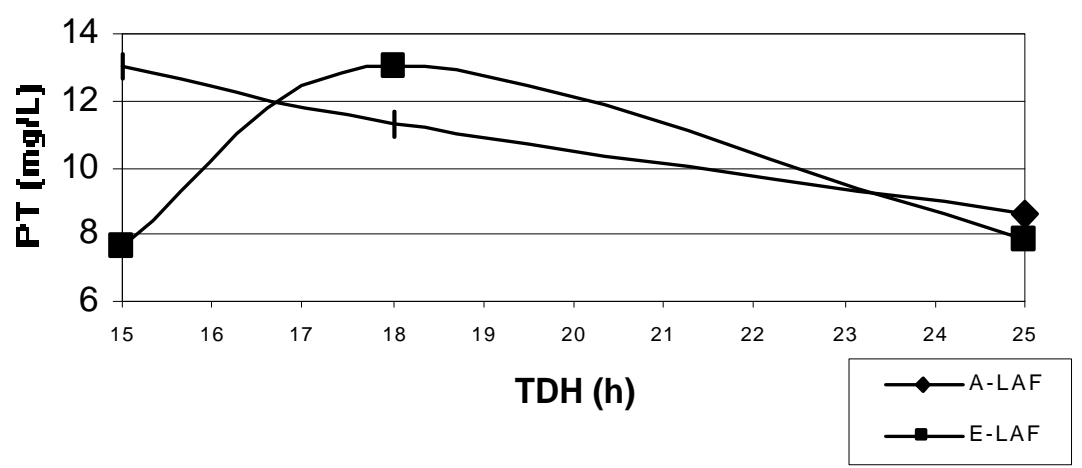

FIGURA 12 - Variação média do Fósforo Total afluente (A) e efluente (E) da LAF em função dos TDH adotados.

\section{CONCLUSÃO}

A LAF demonstrou ser adequada para polimento de sistemas que utilizam reatores UASB como unidade principal de tratamento de anaeróbio de efluentes líquidos de suínos, como discutido anteriormente, atendendo às exigências da Deliberação Normativa COPAM-10/86, artigo 15, para o lançamento de efluentes líquidos em cursos d'água nos parâmetros $\mathrm{pH}$, temperatura, $\mathrm{DBO}_{5}$ e $\mathrm{DQO}_{\mathrm{T}}$. O sistema como um todo demonstrou alta eficiência na remoção de poluentes orgânicos, com valores de eficiência atingindo 93,84 e $85 \%$ de remoção da DQO $_{\mathrm{T}}$ DBO e STV, respectivamente, confirmando, assim, a sua viabilidade no controle da poluição hídrica gerada por granjas suinícolas. Os parâmetros adotados no sistema laboratorial poderão servir de base para implantação de sistemas em escala piloto e plena, respeitando, evidentemente, as condições inerentes a cada caso específico.

\section{AGRADECIMENTOS}

Ao Departamento de Engenharia (DEG) da Universidade Federal de Lavras (UFLA), por ceder o laboratório. Ao Conselho Nacional de Desenvolvimento Científico e Tecnológico $(\mathrm{CNPq})$, pelo apoio financeiro e bolsas concedidas; e a ainda ao Núcleo de Inovação Tecnológica (NIT) (Convênio UFLA/GCT - Global, Ciência \& Tecnologia), pelo apoio.

\section{REFERÊNCIAS BIBLIOGRÁFICAS}

AMERICAN PUBLIC HEALTH ASSOCIATION. Standard methods for the examination of water and wastewater. 20. ed. New York, 1998.
ASSOCIAÇÃO BRASILEIRA DAS INDÚSTRIAS PRODUTORAS E EXPORTADORAS DE CARNE SUÍNA. São Paulo, 2002. Disponível em: <http//www. abipecs.com.br/histprodução.aps >. Acesso em: 20 mar. 2002.

BLEY JÚNIOR, C. Dejeto bom, só aquele que não existe. Disponível em: <http://www.suino.com. br/suino_product.asp?pj\%5Fid=6000\&dept\%Fid=6>. Acesso em: 12 maio 2000.

CAMPOS, C. M. M. Physical aspects affecting granulations in UASB reactors. 1990. $425 \mathrm{f}$. Thesis (PhD) - Universidade de Newcastle, Newcastle, 1990.

CARMO, F. R.; CAMPOS, C. M. M.; BOTELHO, C. G. Desenvolvimento e operação de reator anaeróbio de manta de lodo (RAMAL/UASB), utilizando materiais alternativos. In: CONGRESSO DE INICIAÇÃO CIENTÍFICA DA UNIVERSIDADE FEDERAL DE LAVRAS, 15., 2002, Lavras. Anais... Lavras: UFLA, 2002. p. 157.

CHERNICHARO, C. A. de L. Reatores anaeróbios. Belo Horizonte: UFMG, 1997. 246 p.

SPERLING, M. von. Lagoas de estabilização. Belo Horizonte: UFMG, 1996. v. 3, 134 p.

TEICH, D. H. Vai valer mais que petróleo. Veja, São Paulo, v. 35, n. 1769, p. 14-15, set. 2002. 